\title{
Processing and structure-property relationships of natural rubber/wheat bran biocomposites
}

\author{
Krzysztof Formela $\cdot$ Aleksander Hejna $\cdot$ Lukasz Piszczyk • \\ Mohammad Reza Saeb $\cdot$ Xavier Colom
}

Received: 4 February 2016/ Accepted: 27 July 2016/Published online: 2 August 2016

(C) The Author(s) 2016. This article is published with open access at Springerlink.com

\begin{abstract}
In this work, wheat bran was used as cellulosic filler in biocomposites based on natural rubber. The impact of wheat bran content [ranging from 10 to 50 parts per hundred rubber (phr)] on processing, structure, dynamic mechanical properties, thermal properties, physico-mechanical properties and morphology of resulting biocomposites was investigated. For better characterization of interfacial interactions between natural rubber and wheat bran, achieved results were compared with properties of biocomposites filled with commercially available cellulosic fillers-wood flour and microcellulose. It was observed that wheat bran, unlike commercial cellulosic fillers, contains high amount of proteins, which act like plasticizers having profitable impact on processing, physical, thermo-mechanical and morphological properties of biocomposites. This is due to
\end{abstract}

K. Formela $(\bowtie) \cdot$ A. Hejna · Ł. Piszczyk

Department of Polymer Technology, Gdansk University of Technology, G. Narutowicza Str. 11/12,

80-233 Gdańsk, Poland

e-mail: krzysztof.formela@pg.gda.pl;

kformela.ktp@gmail.com

M. R. Saeb

Department of Resin and Additives, Institute for Color Science and Technology, Teheran, Iran

X. Colom

Department of Chemical Engineering, Universitat

Politècnica de Catalunya Barcelona Tech, Terrassa, Spain better dispersion and distribution of wheat bran particles in natural rubber, which results in reduction of stiffness and porosity of the biocomposites. Regardless of cellulosic filler type, Wolff activity coefficient was positive for all studied biocomposites implying reinforcing effect of the applied fillers, while tensile strength and elongation at break decreased with increasing filler content. This phenomenon is related to restricted strain-induced crystallization of NR matrix due to limited mobility of polymer chains in the biocomposites. Furthermore, this explains negligible impact of particle size distribution, chemical composition and crystallinity degree of applied cellulosic filler on static mechanical properties of highlyfilled NR biocomposites. The conducted investigations show that wheat bran presents interesting alternative for commercially available cellulosic fillers and could be successfully applied as a low-cost filler in polymer composites.

Keywords Wheat bran - Natural rubber . Biocomposites · Processing · Structure-property relationship

\section{Introduction}

Limited petroleum resources, continuously increasing amount of polymeric wastes and higher awareness of the society, are the main economic and environmental factors causing dynamic development of biodegradable 
polymeric materials. Estimated data indicates that production and application of biodegradable polymers in different branches of industry will grow by over $30 \%$ annually (Shen et al. 2009). Therefore, searching for new biodegradable polymers and biocomposites with tailored performance properties (Franciszczak and Błędzki 2015; Kwiecien et al. 2014) and reasonable price (Chikhi et al. 2013; Korol et al. 2015a; Sałasińska and Ryszkowska 2015) received attention nowadays in many academic and industrial scientific centers all over the world.

Special group of biocomposites are wood polymer composites (WPCs) which are defined as materials consisting of one or more cellulosic filler and one or a mixture of polymers. High amount of cellulose-rich by-products, generated from wood and agriculture industry, can be successfully applied as biofillers in polymeric matrix, to reduce material costs and provide specific properties of biocomposites, e.g. low density, high stiffness, corrosion resistance, low hazard, renewable characteristics and biodegradability (Gurunathan et al. 2015; Mohammed et al. 2015; Sobczak et al. 2013). Above mentioned factors account for commonly usage of WPCs as building and automobile products and as environmental friendly alternative for pure polymers (Korol et al. 2015b; Teuber et al. 2016).

It is well known that performance properties of WPCs depend on physical and chemical interactions between polymer matrix and cellulosic filler. Matrixfiller interaction level is governed by the structure of the polymer matrix and characteristics of cellulosic filler. Many attempts have been recently focused on the influence of cellulosic filler characteristics on processing and structure-property relationships of WPCs. Liu et al. (2014) applied wood flour, lignin flour and cellulose flour (the last two were separated from wood flour) in biocomposites based on poly(propylene) (PP) or poly(lactic acid) (PLA). The results confirmed that chemical composition of lignocellulosic flour had significant influence on physical, mechanical and thermal properties of obtained biocomposites, which was also related to the type of the used polymer matrix. Peltola et al. (2014) used five types of cellulosic fillers (wood flour, thermo-mechanical spruce pulp fibers and three types of chemically bleached kraft pulp fibers) as reinforcement of PP or PLA. They reported that cellulosic fibers are dispersed more uniformly in the PLA than in the PP. The best performance properties were achieved for
PLA-based composites reinforced with thermo-mechanical spruce pulp (TMP) fibers. This was related to stiffness of TMP fibers and lignin present in TMP, which might act like a compatibilizer between PLA matrix and the filler phase. Furthermore, the results have shown that in comparison to lignocellulosic fibers, wood flour is not a reinforcing filler. Faludi et al. (2014) used six different commercially available cellulosic fibers (four types of wood fibers, microcrystalline cellulose, ground corn cob) with varying chemical composition and different particle characteristics to prepare biocomposites based on PLA and observed strong interfacial adhesion between PLA matrix and cellulosic fibers. It was also reported that the reinforcing effect was related to the size and aspect ratio of cellulosic fibers and, surprisingly, was independent of their origin (chemical composition).

The present state of knowledge shows that detailed characteristics of cellulosic filler can be a valuable tool for tailoring of biocomposites with desired performance properties. However, the current researches in this field are mainly focused on thermoplastic biocomposites based on polyolefins or on biodegradable aliphatic polyesters (Berthet et al. 2015; Błędzki et al. 2015; Georgiopoulos and Kontou 2015), while correlations between cellulosic fillers characteristics and selected properties of natural rubber as renewable matrix are poorly described in the literature. Wood polymer composites with elastomeric matrix are interesting alternative for thermoplastic WPCs. A comprehensive literature overview about elastomeric composites with lignocellulosic fillers was recently presented by Zhou et al. (2015).

In this work, the potential of wheat bran (WB) as a cellulosic filler for development of biocomposites based on natural rubber (NR) was evaluated. Wheat bran is a solid by-product of food industry, which can be applied as a low-cost, eco-friendly and celluloserich biofiller. However, only a few recently published papers dealt with usage of WB in polymer composites (Błędzki et al. 2014; Hejna et al. 2015). In the light of above mentioned studies, we aimed to examine the effects of the WB content [in range 10-50 parts per hundred of rubber (phr)] on curing characteristics, chemical structure (FTIR analysis), thermal properties (TGA), dynamic mechanical properties (DMA), static mechanical properties (tensile strength, elongation at break, hardness), physical properties (density, porosity), swelling properties (swelling degree, cross-link 
density, sol fraction), and morphology (SEM) of NR/ WB biocomposites. Furthermore, for comprehensive structure-properties relationships assessment and better understanding the interfacial interactions between $\mathrm{NR}$ and WB, the characteristics of NR/WB biocomposites were compared with properties of biocomposites filled with commercially available cellulosic fillers: wood flour (WF) and microcellulose (MC).

\section{Experimental}

\section{Materials}

Natural rubber (NR) type RSS with density $0.92 \mathrm{~g} / \mathrm{cm}^{3}$ was supplied by Guma-Pomorska (Poland).

Wheat bran (WB) was purchased from Młyn Gospodarczy Sp. J. (Poland). Prior to processing, WB biofiller was dried at $80{ }^{\circ} \mathrm{C}$ and then mechanically ground in a co-rotating twin-screw extruder at $180{ }^{\circ} \mathrm{C}$ to obtain particles with a narrow size distribution. Caprez et al. (1986) indicated that modification of WB via thermo-mechanical extrusion insignificantly affects its chemical composition. Chemical composition of WB is shown in Table 1.

Wood flour (WF) Arbocel C350 and microcellulose (MC) Arbocel B800 were purchased from Rettenmaier and Söhne GmbH (Germany) and used as received.

Vulcanization accelerators (TBBS-N-tert-butyl2-benzothiazole sulfonamide, TMTD — tetramethylthiuram disulfide), stearic acid, zinc oxide and sulfur with technical grade purity were supplied by Standard Sp. z o.o. (Poland).

Table 1 Chemical composition of WB

\begin{tabular}{ll}
\hline Components & $\begin{array}{l}\text { Weight } \\
\text { content }(\%)^{\mathrm{a}, \mathrm{b}}\end{array}$ \\
\hline Cellulose & 25 \\
Hemicellulose & 32 \\
Lignin & 5 \\
Proteins & 4 \\
Ashes & 4 \\
Starch & 12 \\
Others (lipids, carbohydrates, & 18 \\
moisture, etc.) & \\
\hline
\end{tabular}

\footnotetext{
a According to Saunders (1978)
}

b According to Caprez et al. (1986)
Biocomposites preparation

Biocomposites were prepared at $70{ }^{\circ} \mathrm{C}$ using a Brabender batch mixer model GMF 106/2 (Germany). The rotational speed of rotors was $100 \mathrm{rpm}$. The mixing time equaled 8 min which included 2 min of preliminary mastication of NR, 4 min of mixing with the cellulosic fillers (WB, WF or MC) and $2 \mathrm{~min}$ of mixing the blend with the sulfur curing system. The content of cellulosic fillers in the biocomposites was altered from 10 to 50 parts per hundred of rubber (phr). For all samples the same curing system samples was used. The curing system composition (phr): zinc oxide 5.0; stearic acid 3.0; TBBS 1.0; TMTD 0.25; sulfur 2.0. After compounding in a batch mixer, the NR/cellulosic filler biocomposites were homogenized using laboratory two roll mills from Buzuluk (Czech Republic).

The obtained composites were compression molded into 2-mm thick samples at $150{ }^{\circ} \mathrm{C}$ and 4.9 $\mathrm{MPa}$ according to determined optimal cure time. Unfilled NR processed in the same conditions was used as reference sample.

\section{Measurements}

Elemental analysis $(\mathrm{C}, \mathrm{H}, \mathrm{N}, \mathrm{S})$ of cellulosic fillers was carried out using a Flash 2000 CHNSO Analyser from Thermo Scientific (USA).

Macro- and microelements content in cellulosic filler was determined by wavelength dispersive X-ray fluorescence spectrometry (WD-XRF) using a spectrometer S8 Tiger 1KW from Bruker (USA).

Particle size distribution of cellulosic fillers was determined by sieve analysis according to our internal laboratory standard. Approximately $100 \mathrm{~g}$ of filler was manually sieved in constant time (30 min), using woven wire cloth sieves with size $1.02,0.75,0.50$, 0.25 and $0.12 \mathrm{~mm}$, respectively.

$\mathrm{X}$-ray diffraction (XRD) measurements of cellulosic fillers were performed using a Bragg-Brentano X'PERT Philips diffractometer (Netherlands) equipped with a $\mathrm{Cu}$ anode $\mathrm{X}$-ray tube and diffracted beam monochromator $(40 \mathrm{kV}, 30 \mathrm{~mA}, \quad \lambda \mathrm{Cu}$ $\mathrm{K} \alpha=0.1542 \mathrm{~nm}$ ). The samples were scanned in an angle range from $5^{\circ}$ to $40^{\circ}$ with $0.02^{\circ}$ step and $1.8 \mathrm{~s}$ per step. No background correction was made.

Curing characteristics were investigated according to ISO 3417 at $150{ }^{\circ} \mathrm{C}$, using Monsanto R100S 
rheometer with oscillating rotor (USA). The rotor oscillation angle was $1^{\circ}$, while torque ranged between 0 and $100 \mathrm{dNm}$. Cure rate index (CRI) values were calculated in accordance with the formula (Menon et al. 1998) (1):

$\mathrm{CRI}=\frac{100}{t_{90}-t_{2}}$

where $t_{90}$-optimum vulcanization time, $\mathrm{min} ; t_{2}-$ scorch time, min.

Chemical structure of cellulosic fillers and biocomposites was determined using Fourier transform infrared spectroscopy (FTIR) analysis performed by means of a Nicolet iS10 spectrometer from Thermo Scientific (USA) equipped with a diamond crystal. Measurements were performed in a reflective absorbance mode (ATR-FTIR), at $1 \mathrm{~cm}^{-1}$ resolution in the range $650-4000 \mathrm{~cm}^{-1}$.

Tensile strength and elongation at break of the obtained vulcanizates were tested according to the standard ISO 37 using a Zwick Z020 testing machine (Germany) with load capacity of $20 \mathrm{kN}$. Tensile tests were performed at a cross-head speed of $500 \mathrm{~mm} / \mathrm{min}$. Direct extension measurements were conducted periodically using an extensometer with sensor arms. Hardness was determined using a Zwick 3130 durometer Shore A (Germany) in accordance with the standard ISO 7619-1. The reported results are the means of 5 measurements per sample.

Dynamic mechanical analysis was performed using DMA Q800 TA Instruments apparatus (USA). Samples cut to the dimensions of $40 \times 10 \times 2 \mathrm{~mm}$ were loaded with a variable sinusoidal deformation force in the single cantilever bending mode at the frequency of $1 \mathrm{~Hz}$ under the temperature rising rate of $4{ }^{\circ} \mathrm{C} / \mathrm{min}$ within the temperature range between -80 and $60{ }^{\circ} \mathrm{C}$.

Swelling degree of biocomposites ( $0.2 \mathrm{~g}$ samples) as function of time was determined by equilibrium swelling in toluene (room temperature). Swelling degree was calculated in accordance with the formula (2):

$Q=\frac{m_{t}-m_{o}}{m_{o}} \times 100 \%$

where $Q$-swelling degree, $\% ; m_{t}$-mass of the sample swollen after time $t, \mathrm{~g} ; m_{o}$-initial mass of sample, g.

Cross-link density of the biocomposites was determined by equilibrium swelling in toluene (room temperature, $72 \mathrm{~h}$ ), according to the Flory-Rehner equation (Flory and Rehner 1943) (3):

$v_{e}=\frac{-\left[\ln \left(1-V_{r}\right)+V_{r}+\chi V_{r}^{2}\right]}{\left[V_{1}\left(V_{r}^{1 / 3}-V_{r} / 2\right)\right]}$

where $v_{e}$-cross-link density, $\mathrm{mol} / \mathrm{cm}^{3} ; V_{r}$-gel volume in the swollen sample; $V_{l}$-solvent molar volume (toluene $=106.2 \mathrm{~cm}^{3} / \mathrm{mol}$ ); $\quad \chi$-polymer-solvent interaction parameter [in the calculations, it was assumed to be 0.393 (López-Manchado et al. 2003)].

The Flory-Rehner equation can be applied for nonfilled compounds, while studied samples contain cellulosic fillers. Kraus correction for filled compounds (Kraus 1963) was applied in order to calculate the actual remaining cross-link density. Cross-link density with Kraus correction was calculated according Eqs. (4) and (5):

$v_{\text {aftercorrection }}=\frac{v_{e}}{1+\mathrm{K} \times \Phi}$

$\Phi=\frac{\varphi_{f} \times \rho_{r} \times m_{0}}{\rho_{f} \times m_{d r y}}$

where $v_{e}$-the measured chemical cross-link density, $\mathrm{mol} / \mathrm{cm}^{3} ; v_{\text {after correction - the actual chemical cross- }}$ link density, $\mathrm{mol} / \mathrm{cm}^{3} ; \mathrm{K}$ - constant characteristic of the filler but independent of the solvent; $\phi_{f}$-the calculated volume fraction of filler in the sample; $\rho_{\mathrm{r}}$ the density of studied compound, $\mathrm{g} / \mathrm{cm}^{3} ; \mathrm{m}_{0}$ - the weight of sample before extraction, $\mathrm{g} ; \rho_{\mathrm{r}}$ - the density of filler, $\mathrm{g} / \mathrm{cm}^{3} ; \mathrm{m}_{\mathrm{dry}}$ - the weight of sample after extraction, $\mathrm{g}$

Sol fraction was determined as mass difference of biocomposites before swelling $\left(\mathrm{W}_{1}\right)$ and after extraction $\left(\mathrm{W}_{2}\right)$, according to Eq. (6):

Sol fraction $=\frac{\mathrm{W}_{1}-\mathrm{W}_{2}}{\mathrm{~W}_{1}} \times 100 \%$

The density of the samples was measured based on the Archimedes method, as described in ISO 2781. Accordingly, all measurements were carried out at room temperature in methanol medium.

Thermogravimetric analysis (TGA) was performed on a NETZSCH TG 209 apparatus. Samples of biocomposites weighing approx. 5-mg were placed in a corundum crucible. The measurement was conducted in the temperature range $25-600{ }^{\circ} \mathrm{C}$ and under nitrogen atmosphere, at a heating rate of $20{ }^{\circ} \mathrm{C} /$ $\min$. 
The morphology of biocomposites after extraction in toluene (at room temperature, $72 \mathrm{~h}$ ) was observed with a JEOL 5610 scanning electron microscope. Before measurement the samples were covered with a fine gold-palladium layer in order to increase their conductivity in a vacuum chamber.

\section{Results and discussion}

\section{Characteristics of cellulosic fillers}

The characteristics of WB, WF and MC fillers determined by elemental analysis, WD-XRF analysis, FTIR and XRD are presented in Table 2. Based on literature data (Caprez et al. 1986; Saunders 1978) and presented results, noticeable difference between WB and other applied biofillers results from the presence of proteins, which was confirmed by a high content of nitrogen. Furthermore, wheat bran was characterized by higher content of macro- and microelements, which could enhance activity of enzymes and microorganisms during biodegradation of biocomposites (Tomaszewska-Ciosk et al. 2013). This phenomenon should be evaluated in further studies on this field.

The particle size distribution of the used cellulosic fillers is presented in Fig. 1. Size of filler particles imposes a significant influence on its dispersibility in the polymer matrix. MC filler was characterized by the smallest size with $\sim 80 \mathrm{wt} \%$ of particles below
$0.12 \mathrm{~mm}$. It was observed that dimensions of WB filler particles $(\sim 95 \mathrm{wt} \%$ of particles below $0.50 \mathrm{~mm})$ was slightly higher comparing to WF particles ( $\sim 100 \mathrm{wt} \%$ of particles below $0.50 \mathrm{~mm}$ ). This proves that using a co-rotating twin screw extrusion is an effective grinding method for wheat bran, which could be applied in industry.

FTIR spectra of applied cellulosic fillers are presented in the Fig. 2. Signal (a) characteristic for stretching vibrations of hydroxyl groups was observed at $3300-3350 \mathrm{~cm}^{-1}$. The bands (b) in the range of $2940-2860 \mathrm{~cm}^{-1}$ were attributed to the symmetric and asymmetric stretching vibrations of $\mathrm{C}-\mathrm{H}$ bonds in $\mathrm{CH}_{2}$ groups present in aliphatic chains and $\mathrm{CH}_{3}$ end groups. Absorbance maxima around 1740 and $1640 \mathrm{~cm}^{-1}$ (signals $\mathrm{c}$ and d), could be associated with the stretching vibrations of unconjugated $\mathrm{C}=\mathrm{O}$ and $\mathrm{C}=\mathrm{C}$ bonds in cellulose, hemicellulose and lignin (Yona et al. 2014). The absorption band (e) around $1510 \mathrm{~cm}^{-1}$ was related to the stretch of aromatic rings present in lignin (Colom et al. 2003), therefore this peak band was not observed for microcellulose. Signal (f) around $1460 \mathrm{~cm}^{-1}$ can be associated with $\mathrm{CH}_{2}$ and HOC in-plane bending vibrations, characteristic for carbohydrates (Ciolacu et al. 2011). Signal (g) in the range of $1360-1310 \mathrm{~cm}^{-1}$ is related to the $\mathrm{OH}$ groups plane deformation vibrations, while band (h) at $1230 \mathrm{~cm}^{-1}$ is attributed to the stretching of $\mathrm{C}-\mathrm{O}$ and $\mathrm{C}=\mathrm{O}$ bonds (Schwanninger et al. 2004). In the range of $1160-1010 \mathrm{~cm}^{-1}$ there are present the absorption
Table 2 Elemental analysis and crystallinity of applied biofillers
TCI Total Crystallinity Index, LOI Lateral Order Index, $H B I$ hydrogen bond intensity, $C I$ Crystallinity Index based on the empirical Segal's equation

\begin{tabular}{|c|c|c|c|c|c|}
\hline Item & Method & Unit & WB & WF & $\mathrm{MC}$ \\
\hline $\mathrm{C}$ & \multirow[t]{3}{*}{ Elemental analysis } & \multirow[t]{3}{*}{ wt $\%$} & 44.92 & 48.20 & 43.89 \\
\hline $\mathrm{H}$ & & & 6.26 & 5.82 & 6.12 \\
\hline $\mathrm{N}$ & & & 2.48 & 1.06 & 0.43 \\
\hline $\mathrm{K}$ & \multirow[t]{8}{*}{ WD-XRF } & \multirow[t]{8}{*}{$\mathrm{wt} \%$} & 1.26 & 0.14 & - \\
\hline $\mathrm{P}$ & & & 0.62 & - & - \\
\hline $\mathrm{Mg}$ & & & 0.22 & - & - \\
\hline$S$ & & & 0.14 & 0.03 & 0.02 \\
\hline $\mathrm{Ca}$ & & & 0.08 & 0.16 & 0.04 \\
\hline $\mathrm{Cl}$ & & & 0.07 & - & - \\
\hline $\mathrm{Fe}$ & & & 0.01 & 0.02 & - \\
\hline $\mathrm{Si}$ & & & - & 0.19 & - \\
\hline TCI $(-1371 / 2900 \mathrm{~cm})$ & \multirow[t]{3}{*}{ FTIR } & \multirow[t]{3}{*}{-} & 1.37 & 1.23 & 1.11 \\
\hline LOI $\left(\begin{array}{l}-1 \\
1430 / 893 \mathrm{~cm}\end{array}\right)$ & & & 0.63 & 0.87 & 0.79 \\
\hline HBI $(3336 / 1336 \mathrm{~cm})$ & & & 1.03 & 0.95 & 1.08 \\
\hline CI & XRD & $\%$ & 13.7 & 51.4 & 59.0 \\
\hline
\end{tabular}




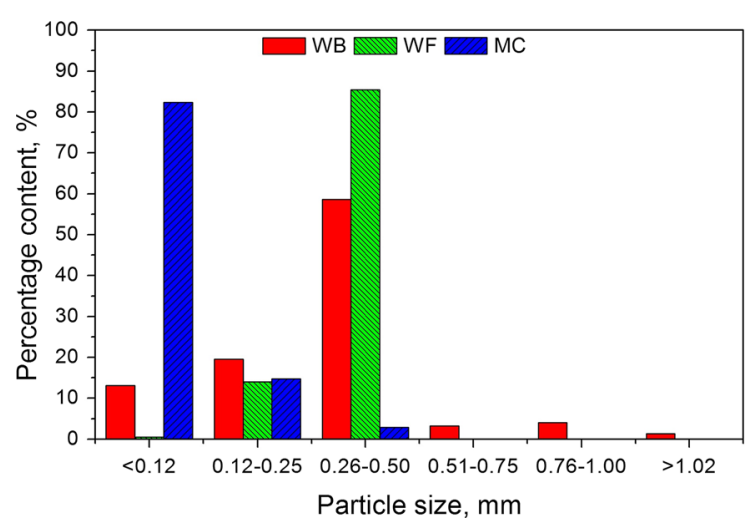

Fig. 1 The particle size distribution of used cellulosic fillers

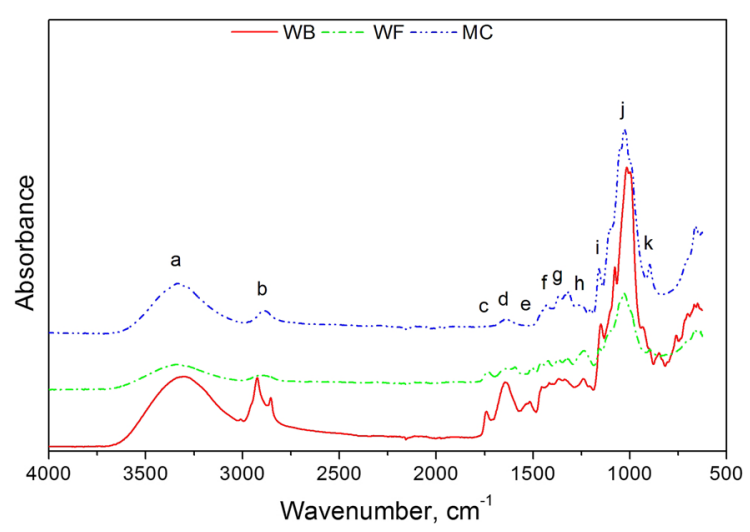

Fig. 2 FTIR spectra of used cellulosic fillers

bands (i) and (j), which are characteristic for asymmetric stretching vibrations of $\mathrm{C}-\mathrm{O}-\mathrm{C}$ groups and $\mathrm{C}-$ $\mathrm{O}, \mathrm{C}=\mathrm{C}$ and $\mathrm{C}-\mathrm{C}-\mathrm{O}$ stretching, respectively (Xu et al. 2013). Signal (k) observed around $890 \mathrm{~cm}^{-1}$ is attributed to antisymmetric out-of-phase ring stretching in carbohydrate structure of used biofillers (Faix 1991). The intensity of band (k) at $890 \mathrm{~cm}^{-1}$ is very sensitive to the degree of crystallinity of cellulose, which is related to changes in angles around $\beta-1,4-$ glycosidic linkages and possible reorganization of hydrogen bonds in cellulose (Proniewicz et al. 2001). Crystallinity of used fillers was evaluated using total crystallinity index $\left(\mathrm{TCI}_{1371 / 2900 \mathrm{~cm}}^{-1}\right)$, lateral order index $\left(\mathrm{LOI}_{1430 / 893 \mathrm{~cm}}^{-1}\right)$ and hydrogen bond intensity $\left(\mathrm{HBI}_{3336 / 1336}^{-1} \mathrm{~cm}\right)$ based on the absorption ratios proposed in works (Kljun et al. 2011; Yue et al. 2015). Above mentioned parameters, presented in Table 2, are strictly related to degree of crystallinity and status of the intermolecular regularity.
Surprisingly, the highest TCI value determined for WB indicates the highest content of crystalline cellulose, while the smallest TCI was observed for MC filler. LOI parameter is correlated to the overall degree of alignment in the cellulose, while hydrogen bond intensity (HBI) is related to the crystal system and the degree of intermolecular regularity as well as the amount of bound water. The highest LOI value was observed for WF filler, while the smallest for WB filler. On the other hand, HBI parameter increased in order $\mathrm{WF}<\mathrm{WB}<\mathrm{MC}$. Generally, when LOI decreases or HBI increases, the crystallinity of cellulose decreases. However, these results do not correspond with determined TCI values, which could be due to chemical composition of used filler.

For example, wheat bran contains proteins with amide and carbonyl groups. These polar groups are able to enhance formulation of hydrogen bonds in cellulose, which would reduce its crystallinity. Furthermore, it should be mentioned, that proteins present in biofillers have important influence on intensity of bands in FTIR spectra, which is due to similar position of infrared bands characteristic for cellulose and proteins (Barth 2007).

Therefore, more detailed characteristics of crystallinity in cellulosic fillers could be achieved using X-ray diffraction (French 2014; French and Santiago Cintrón 2013), Raman spectroscopy (Agarwal et al. 2010), nuclear magnetic resonance (Bernardinelli et al. 2015), differential scanning calorimetry (Bertran and Dale 1986) or combination of these methods. Amongst them, X-ray diffraction (XRD) gives the most direct results and quantitative information. Therefore, for better characteristics of crystallinity in cellulosic fillers XRD measurements were performed and obtained XRD spectra are presented in the Fig. 3.

Presented results show that wheat bran contains mainly amorphous cellulose, while its semi-crystalline form is presented in microcellulose and wood flour (Nam et al. 2016). Small differences in intensity of XRD patterns observed in case of MC and WF biofillers, can be related to diverse type of wood used during preparation of wood flour. Amorphous form of wheat bran is related to thermo-mechanical milling prior application as a biofiller (please see Materials section). This suggests that heat and mechanical stress acting on wheat bran during twin screw extrusion are suitable for transformation of crystalline cellulose into its amorphous form. 


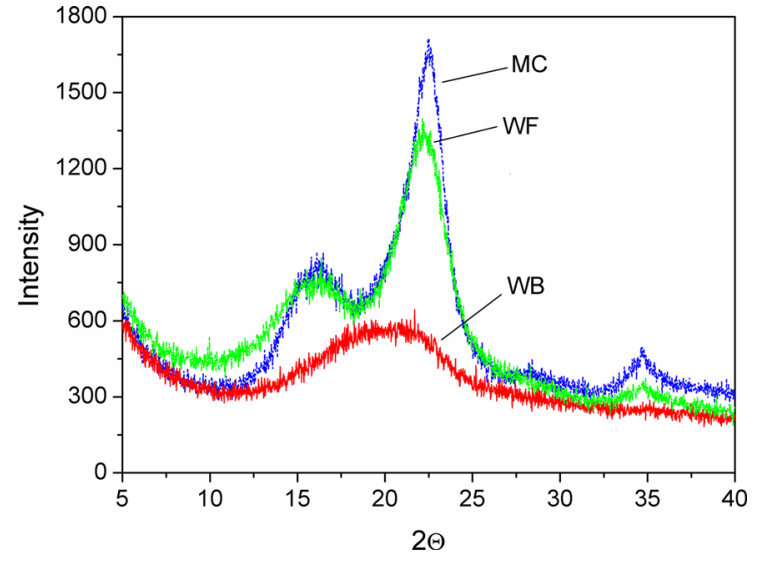

Fig. 3 XRD patterns of cellulosic fillers

The crystallinity index (CI) is determined using equal (7):

$\mathrm{CI}(\%)=\left(1-\frac{h_{a m}}{h_{c r}}\right) \times 100 \%$

where $h_{c r}$ is height of the highest peak, $h_{a m}$ is the intensity of diffraction attributed to amorphous cellulose. During calculation the intensity height for amorphous phase is taken $18^{\circ}$, based on the methodology described in work (Yue et al. 2015). Crystallinity index values are calculated from the original XRD data. The obtained results of CI calculation are presented in Table 2. The CI values, determined using XRD, indicate that the degree of crystallinity of cellulose present in used biofillers increases in the order $\mathrm{WB}<\mathrm{WF}<\mathrm{MC}$. On the other hand, TCL values calculated basing on FTIR spectra, showed opposite trend ( $\mathrm{MC}<\mathrm{WF}<\mathrm{WB}$ ). This indicates that absorption ratios used during calculation of TCI, LOI and HBI parameters are not valid for multi-component samples (in this case: wheat bran, wood flour). This problem was pointed by Karimi and Teherzadeh (2016) in recently published comprehensive review about analytical methods used for compositional, imaging, and crystallinity measurements of lignocelluloses.

\section{Curing characteristics}

The influence of cellulosic filler type and content on curing characteristics of NR/cellulosic filler biocomposites is presented in Table 3 and Fig. 4. It was observed that curves for NR/WB and NR/WF biocomposites shown similar trend, while curing behavior of NR/MC biocomposites was clearly different. The increase of wheat bran or wood flour content in NR-based biocomposites had insignificant impact on minimal torque. This suggests good processing properties of the highly filled (50 phr of cellulosic filler) NR/WB and NR/WF biocomposites, which was comparable to unfilled NR. On the other hand, higher content of microcellulose in NR/MC biocomposites caused increase of minimal torque values. This indicates better dispersion of MC filler in natural rubber matrix, which is related to lower particles size of this filler comparing to WB and WF fillers (see Fig. 1). Maximal torque and torque increment $(\Delta \mathrm{M})$ increase with higher content of cellulosic filler, regardless of its type. The increase of maximal torque and $\Delta \mathrm{M}$ resulting from limited mobility of polymer chains is related to NR/cellulosic filler interactions and cross-link density of biocomposites (Jacob et al. 2004; Karaağaç 2014). This phenomenon has significant impact on stiffness and shear modulus of biocomposites. Among all studied samples, NR/ WB biocomposites were characterized by the lowest maximal torque and $\Delta \mathrm{M}$ values. This suggests that proteins present in wheat bran, can act like plasticizers in prepared biocomposites (Selmin et al. 2015), which reduced their stiffness.

In case of biocomposites filled with WB or WF, increasing content of cellulosic filler caused decrease of scorch time. Higher content of WB in NR-based composites cause increase of optimal cure time, while for NR/WF composites opposite trend was observed. It is worth to notice that results for filled and unfilled NR were comparable. Slight difference between NR/ $\mathrm{WB}$ and NR/WF biocomposites could be due to varying particle size distribution (see Fig. 1) and differences in cellulosic filler characteristics (e.g. content of proteins, sulfur or microelements, crystallinity degree-see Tables 1,2). These parameters could affect matrix-filler interactions, thus curing efficiency of biocomposites. NR/MC biocomposites were characterized by lower values of scorch time and optimal cure time comparing to unfilled NR, NR/WB and NR/WF biocomposites. This is due to small size particles of MC, which allows good dispersion of biofiller into NR matrix and improves interactions between cellulosic filler surface and NR matrix (Sareena et al. 2012b). It was observed that increasing content of MC filler in biocomposites decreases scorch 
Table 3 Curing characteristics of biocomposites

\begin{tabular}{|c|c|c|c|c|c|c|c|c|c|c|}
\hline \multirow{2}{*}{$\frac{\text { Component }}{\text { Natural rubber (NR) }}$} & \multicolumn{10}{|c|}{ Sample } \\
\hline & 100 & 100 & 100 & 100 & 100 & 100 & 100 & 100 & 100 & 100 \\
\hline Wheat bran (WB) & - & 10 & 30 & 50 & & & & & & \\
\hline Wood flour (WF) & & & & & 10 & 30 & 50 & & & \\
\hline Microcrystalline cellulose (MC) & & & & & & & & 10 & 30 & 50 \\
\hline \multicolumn{11}{|l|}{ Curing characteristiscs at $150{ }^{\circ} \mathrm{C}$} \\
\hline Minimal torque $(\mathrm{dNm})$ & 2.4 & 1.7 & 2.2 & 2.6 & 2.5 & 2.9 & 2.4 & 2.9 & 7.7 & 11.7 \\
\hline Maximal torque $(\mathrm{dNm})$ & 24.0 & 24.4 & 31.2 & 37.4 & 28.4 & 34.3 & 39.6 & 29.2 & 39.7 & 47.5 \\
\hline$\Delta \mathrm{M}(\mathrm{dNm})$ & 21.6 & 22.7 & 29.0 & 34.8 & 25.9 & 31.5 & 37.2 & 26.3 & 32.0 & 35.8 \\
\hline Scorch time $\left(t_{2}, \min \right)$ & 5.8 & 5.9 & 5.1 & 5.3 & 5.7 & 5.3 & 5.1 & 1.3 & 1.0 & 0.9 \\
\hline Optimum cure time $\left(\mathrm{t}_{90}, \mathrm{~min}\right)$ & 7.5 & 8.2 & 8.2 & 8.7 & 7.9 & 7.6 & 7.6 & 3.2 & 3.3 & 3.5 \\
\hline Cure rate index $\left(\mathrm{CRI}, \mathrm{min}^{-1}\right)$ & 58.8 & 43.5 & 32.3 & 29.4 & 45.5 & 43.5 & 40.0 & 52.6 & 43.5 & 38.5 \\
\hline
\end{tabular}

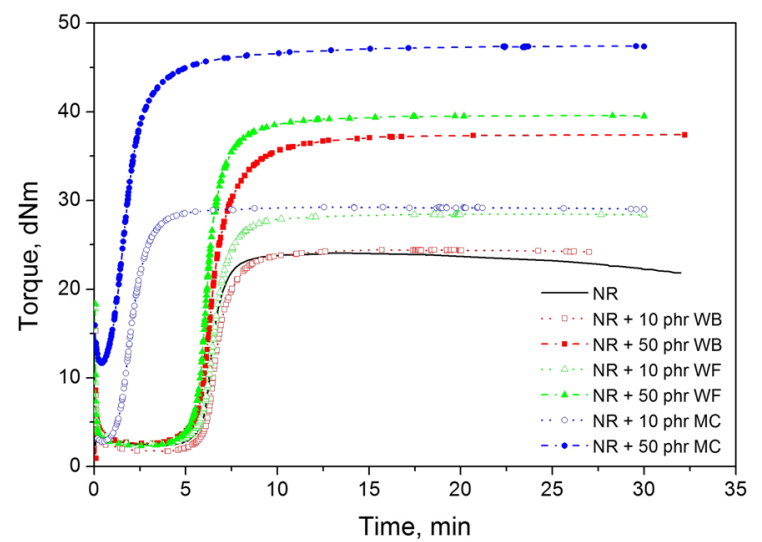

Fig. 4 Curing curves for natural rubber/cellulosic filler biocomposites

time and increases optimal cure time. It could be surprising, because according to literature the scorch time and optimal cure time of elastomer/cellulosic fillers composites tended to decrease consistently with increasing filler loading (Hong et al. 2011; Ismail et al. 2002; Sareena et al. 2012a). This trend is explained by prolonged processing time of the biocomposites on the mills, which is necessary to obtain proper homogeneity of the material. Furthermore, increasing content of cellulosic filler (increasing viscosity) enhanced shear force acting on the processed material, therefore more heat is generated due to additional friction. It should be noticed that studied biocomposites were obtained at elevated temperature $\left(70{ }^{\circ} \mathrm{C}\right)$ using an internal mixer, which reduced the viscosity of biocomposites and decreased time of their processing. Moreover, comparing to two-roll mills, using of internal mixer allows generation of different type of shear forces which affect dispersion of components and final homogeneity of biocomposites. Regardless of type of cellulosic filler, cure rate index (CRI) decreases with increasing content of filler. This indicates that used cellulosic fillers hinder vulcanization of biocomposites. This phenomenon is due to possible adsorbing of the curing system (e.g. activators, accelerators) by biofillers and limited mobility of NR molecules related to good dispersion of filler in NR matrix (Jiang et al. 2013; Raza et al. 2014). For better presentation of biocomposites' curing behavior, selected curing curves are shown in the Fig. 4. It was noticed that addition of cellulosic filler prevents adverse reversion of NR matrix, which was observed for unfilled NR during curing in prolonged time (in study case after $15 \mathrm{~min}$ ). This phenomenon may be due to presence of phenolic compounds in cellulosic fillers, which limits thermo-oxidation of biocomposites.

Presented results confirm significant influence of chemical composition and particle size distribution of biofillers on curing behavior of studied biocomposites. For better understanding of NR-cellulosic filler interactions, reinforcing activity of wheat bran, wood flour and microcellulose into studied biocomposites was evaluated using Wolff activity coefficient $-\alpha_{F}$. Correlation between $\Delta M_{\text {spec }}$ and $\alpha_{F}$ was calculated according Eqs. (8) and (9):

$\Delta M_{\text {spec }}=\frac{\Delta M_{x}}{\Delta M_{0}}-1$ 


$$
\Delta M_{\text {spec }}=\alpha_{F} \cdot \frac{m_{x}}{m_{p}}
$$

where $\Delta M_{x}$ - the torque increment of the vulcanizate containing $\mathrm{x}$ phr of filler during vulcanization, $\mathrm{dNm}$; $\Delta M_{O}$ - the torque increment of unfilled vulcanizate, $\mathrm{dNm} ; m_{x}$-weight of added filler, $\mathrm{g} ; m_{p}$-weight of polymer in vulcanizate, $g$

The reinforcing amount of filler is defined as active for positive $\alpha_{F}$ values and inactive for negative $\alpha_{F}$ values. As presented in Fig. 5, all studied biocomposites was characterized by positive Wolff activity coefficient, which suggests increase of reinforcing effect of applied cellulosic fillers with increasing content of filler (Kramárová et al. 2007). However, this effect was less visible for NR/WB biocomposites, which confirms partial plasticizing of NR matrix by proteins present in WB filler.

\section{Physico-mechanical properties}

The estimated physico-mechanical properties are presented in Table 4. As could be expected, in most cases incorporation of cellulosic fillers into the NR matrix caused noticeable drop in tensile strength and elongation at break. The exception is sample $\mathrm{NR}+10$ phr MC, which tensile strength and elongation at break values were comparable to unfilled NR (reference sample). This is related to small size particles of MC, which enhanced matrix-filler interactions. Furthermore, it was noticed that for highly filled NR biocomposites tensile strength and elongation at break values were comparable. Observed

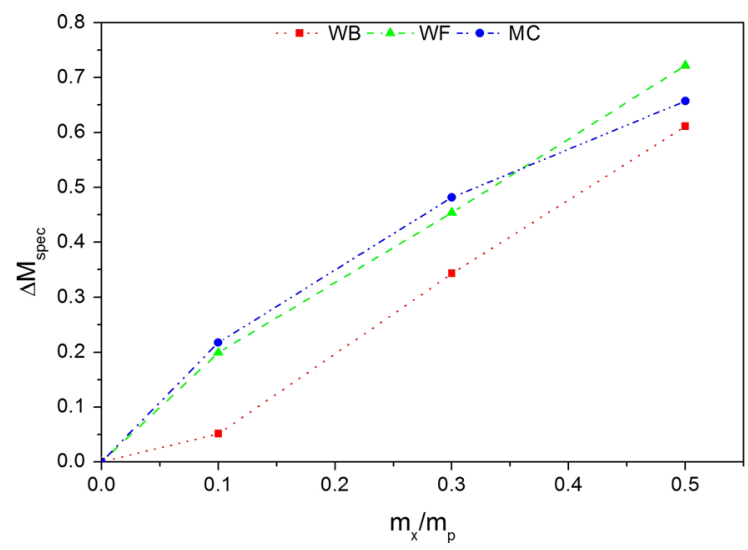

Fig. 5 Dependence torque increment of biocomposites according to Wolff on filler content deterioration of mechanical properties of biocomposites can be explained by weak compatibility between NR matrix and cellulosic fillers. On the other hand, as mentioned above, positive value of Wolff activity coefficient (see Fig. 5) suggests reinforcing effect of cellulosic fillers, which may be surprising and confusing. This phenomenon is probably due to the strain inducted crystallization of NR matrix (Brüning et al. 2012; Ren et al. 2015). During tensile test a part of NR turns the amorphous rubber into a semi-crystalline material. Highly oriented crystallites are acting like active filler particles or physical cross-links, which increases the tensile strength. The stress-strain curves and pictures of biocomposites samples after tensile tests are presented in Fig. 6. It was observed that for $\mathrm{NR} /$ cellulosic filler biocomposites strain-induced crystallization was restricted. Incorporation of higher amount of filler to NR matrix limited mobility of polymer chains and their orientation during stretching, which have significant impact on mechanical properties of obtained composites (Khan et al. 2013). Limited mobility of natural rubber chains shifted the onset of strain-induced crystallization to smaller strains comparing to unfilled NR. These corresponded with "whitening" visible on samples after tensile tests and with increasing values of modulus at 100 and $300 \%$ elongation, determined for the biocomposites. Limited strain-induced crystallization of NR matrix explains also insignificant influence of chemical composition and particle size distribution of cellulosic fillers on static mechanical properties of NR biocomposites filled with $50 \mathrm{phr}$ of lignocellulose filler, which were comparable in the studied case.

Furthermore, it can be seen that increasing amount of incorporated filler results in enhanced hardness of the biocomposites. This confirms increased stiffness of the biocomposites due to limited mobility of NR chains. It was noticed that higher content of cellulose present in biofiller resulted in improvement of biocomposites' hardness, while the presence of proteins (sample NR/WB) in cellulosic filler caused opposite effect. Summing up, differences between mechanical properties of biocomposites filled with WB, WF and $\mathrm{MC}$ are related to particle size distribution and content of proteins in used fillers.

Theoretical and experimental values of density of composites filled with different amount of cellulosic filler are shown in the Table 4. Theoretical density of composites was calculated using the Eq. (10): 


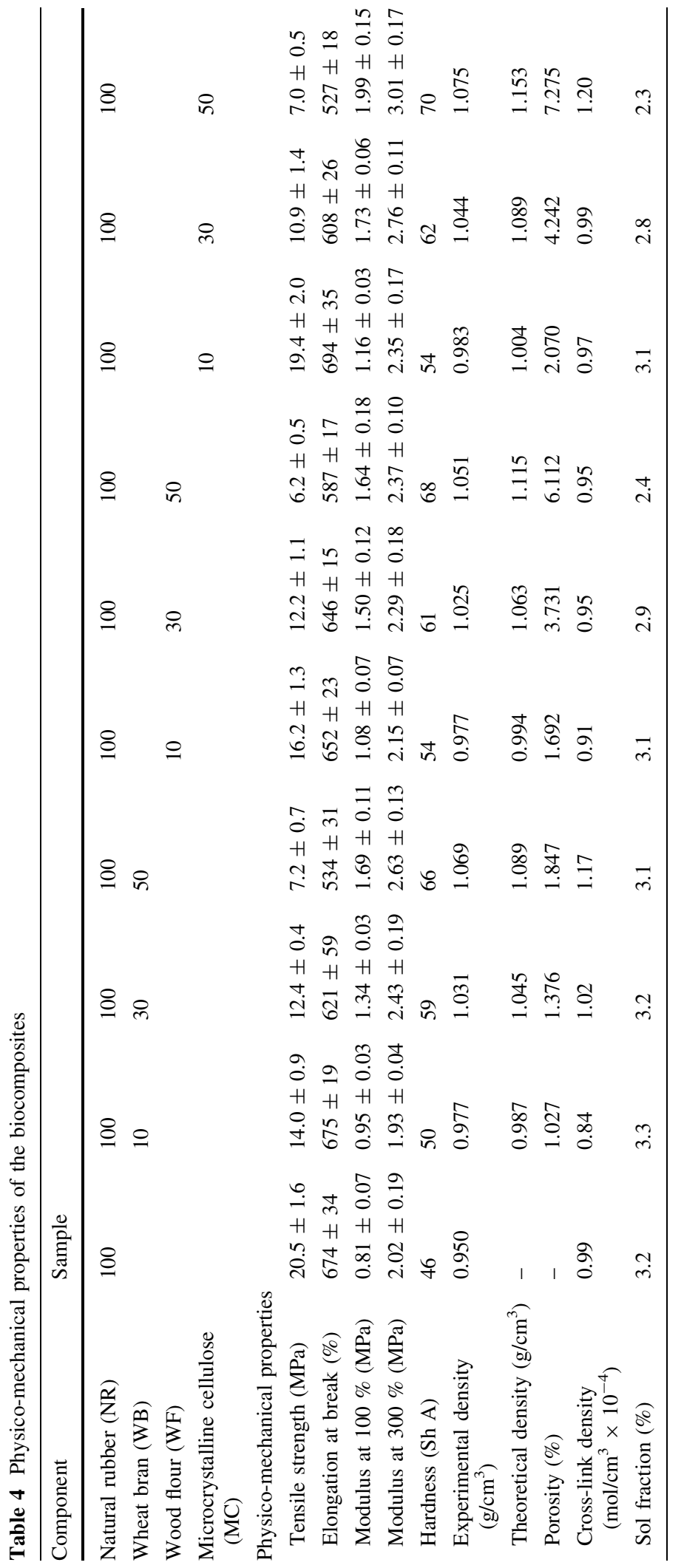



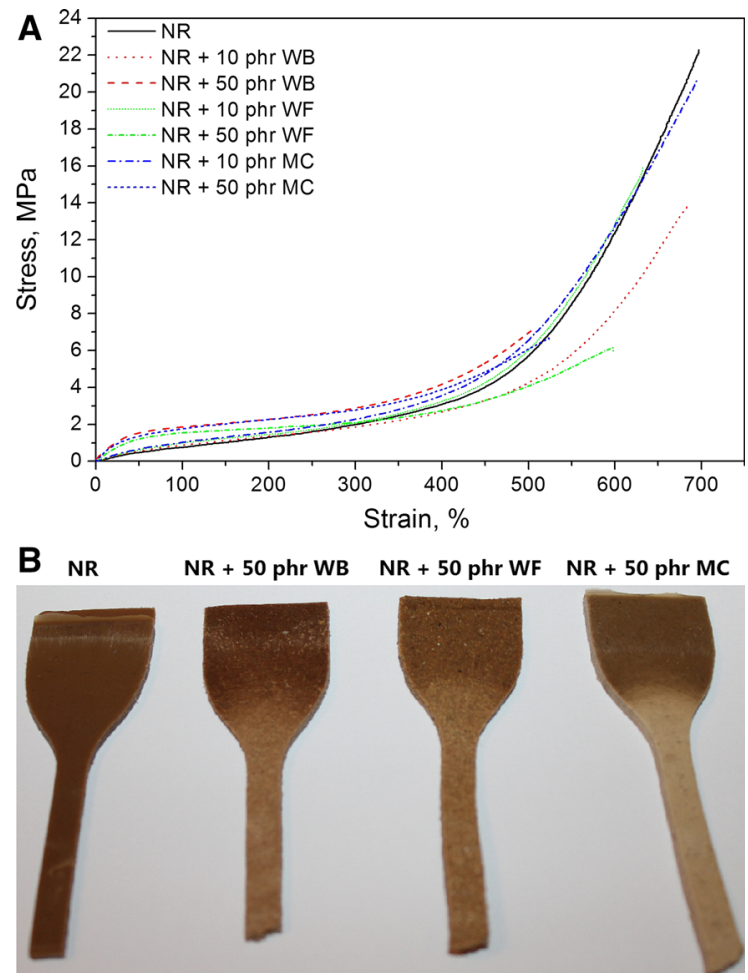

Fig. 6 a Stress-strain curves determined for biocomposites and b samples after tensile tests

$\rho_{C}=\rho_{N R}(1-X)+\rho_{F} X$

where $\rho_{C}$ is the density of the composite, $\mathrm{g} / \mathrm{cm}^{3} ; \rho_{N R}$ is the density of the natural rubber $\mathrm{g} / \mathrm{cm}^{3} ; \rho_{F}$ is the density of the filler, $\mathrm{g} / \mathrm{cm}^{3}$ and $X$ is the fraction of the filler.

Using the theoretical and experimental values of the density, values of composite's porosity were also calculated according to formula (11):

$p=\left(\rho_{\text {theo }}-\rho_{\exp }\right) / \rho_{\text {theo }} \times 100 \%$

where $p$ is the porosity of the material, $\%$; $\rho_{\text {theo }}$ is the theoretical value of density, $\mathrm{g} / \mathrm{cm}^{3}$ and $\rho_{\text {exp }}$ is the experimental value of density of biocomposite, $\mathrm{g} / \mathrm{cm}^{3}$.

Differences in the densities between composites are related to the applied fillers and porosity of studied biocomposites. The ascending trend in the density of green composites prepared in this work upon filler content is in good agreement with previous studies (Datta and Głowińska 2011; Li et al. 2008). The highest values were noticed for NR/MC biocomposites, which was expected considering the density of fillers $\left(1.398,1.484\right.$ and $1.605 \mathrm{~g} / \mathrm{cm}^{3}$ for WB, WF and
MC, respectively). NR/WB biocomposite samples showed higher values of density in comparison to NR/ WF biocomposites, which not correlated with the theoretical values. Such phenomenon can be associated with different porosity of the biocomposites. It can be seen that incorporation of wheat bran into natural rubber matrix resulted in the lowest value of porosity, which can be related to the chemical composition and crystallinity degree of applied filler. Comparing to wood flour and microcellulose, wheat bran contains significant amount of proteins and lipids, which can act like plasticizers, simultaneously enhancing the molecular motion and facilitating the fitting of WB particles into pores between polymer chains (Selmin et al. 2015; Stein and Greene 1997; Stein et al. 1999). Furthermore, amorphous structure of cellulose present in WB could enhance matrix-filler interactions (Avolio et al. 2015; Tsuboi et al. 2012).

In the Fig. 7 plots of swelling degree of biocomposites in toluene are presented. For all studied samples rapid absorbance of solvent is observed during the first hours of immersion, later slowing and reaching the plateau after 48-72 h. Therefore it can be stated that studied biocomposites follow Fickian behavior (Shen and Springer 1976). It can be seen that the incorporation of cellulosic fillers decreased the uptake of toluene for all analyzed samples, which indicates increasing cross-link density of the biocomposites. However, it should be mentioned that determined swelling curves do not include the volume of fillers present in the biocomposites, which has a significant influence on the apparent cross-link density. Therefore, cross-link density with

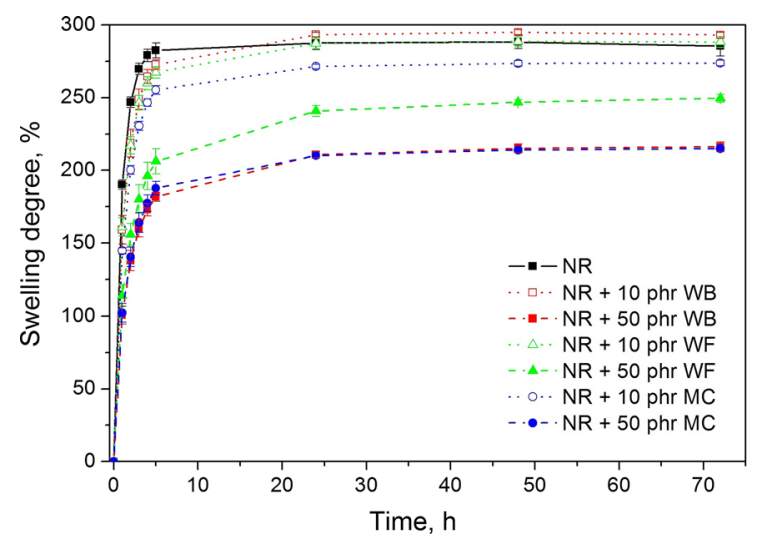

Fig. 7 Swelling degree of biocomposites as function of time (swelling conducted in toluene at room temperature) 
Kraus correction and sol fraction values are presented in Table 4. It was observed that cross-link density of the biocomposites increase with increasing content of cellulosic filler, which corresponds with the content of swelling and sol fraction. Comparing to $\mathrm{WB}$ and $\mathrm{MC}$, the increase of content of WF filler in biocomposites has small impact on change of their cross-link density. This phenomenon could be related to diverse type of wood used during preparation of wood flour filler, which may affect matrix-filler interactions and thus curing efficiency of NR/WF biocomposites.

Samples modified with wheat bran particles showed slightly higher values of sol fraction than NR biocomposites filled with WF or MC. This phenomenon can be related to amorphous structure of wheat bran (see Fig. 3) and higher content of nonstructural wood constituents (Horvath 2006) in this cellulosic filler comparing to wood flour or microcellulose (see Table 2).

\section{FTIR analysis}

Based on economic and environmental aspects of the intended application, further research was performed for the biocomposites with the highest (50 phr) content of cellulosic fillers, which showed satisfactory processing and physico-mechanical properties.

In the Fig. 8 there are presented FTIR spectra of analyzed biocomposites. The FTIR analysis demonstrated that type of cellulosic filler has a negligible influence on chemical structure of the obtained NR based composites. Small absorption band (a) characteristic for stretching vibrations of hydroxyl groups was observed at $3300 \mathrm{~cm}^{-1}$ for NR/cellulosic filler biocomposites. At the same time the absorption maximum at $3290 \mathrm{~cm}^{-1}$ for unfilled NR was noticed. This suggests presence of proteins (monopeptides and dipeptides) in natural rubber (Manaila et al. 2015). The bands (b, c and d) in the range of $2960-2850 \mathrm{~cm}^{-1}$ were attributed to the symmetric and asymmetric stretching vibrations of $\mathrm{C}-\mathrm{H}$ bonds in $\mathrm{CH}_{2}$ groups present in aliphatic elastomer chains and $\mathrm{CH}_{3}$ end groups. Signals (e and f) around 1740 and $1660 \mathrm{~cm}^{-1}$ are associated with the stretching vibrations of unconjugated $\mathrm{C}=\mathrm{O}$ and $\mathrm{C}=\mathrm{C}$ bonds. Such bonds can be present in natural rubber after processing, but the intensity of responsible signals is slightly higher for modified samples, which is related to presence of such bonds also in cellulose, hemicellulose and lignin,

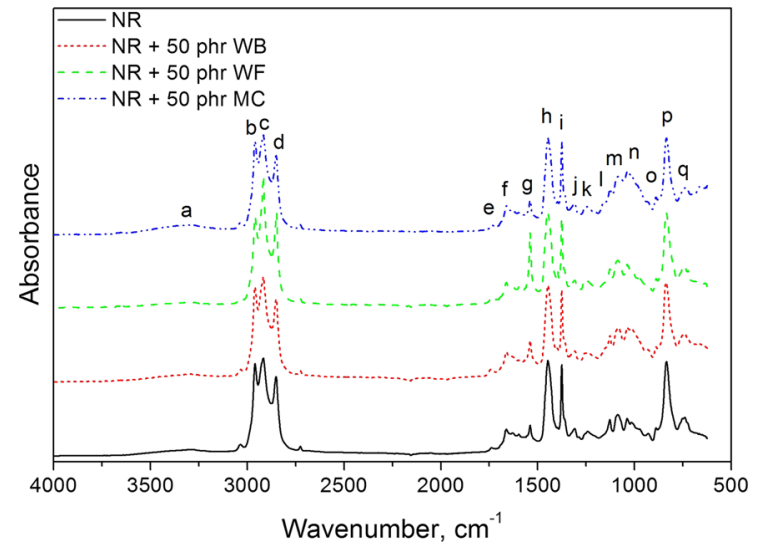

Fig. 8 FTIR spectra of studied biocomposites

especially after partial degradation due to biocomposites' processing (Budarin et al. 2010). The absorption band $(\mathrm{g})$ around $1540 \mathrm{~cm}^{-1}$ is related to the presence of $\mathrm{C}=\mathrm{C}$ double bonds in the biocomposites' structure. As it can be seen, the highest intensity of this band was observed for sample NR $+50 \mathrm{phr}$ WF. This could be related to curing efficiency of NR/WB biocomposite, which corresponds with the estimated cross-link density value. Signal (h) around $1450 \mathrm{~cm}^{-1}$ is associated with scissor vibrations of $\mathrm{C}-\mathrm{H}$ bonds in $\mathrm{CH}_{2}$ groups in aliphatic chains. Absorption maximum (i) at $1375 \mathrm{~cm}^{-1}$ is related to the vibrations of $\mathrm{C}-\mathrm{H}$ bonds in $\mathrm{CH}_{3}$ end groups. Band (j) at $1309 \mathrm{~cm}^{-1}$ might be attributed to the $\mathrm{OH}$ groups plane deformation vibrations. Signal $(\mathrm{k})$ at $1243 \mathrm{~cm}^{-1}$ and bands (1, $\mathrm{m}$ and $\mathrm{n}$ ) in the range of $1125-1035 \mathrm{~cm}^{-1}$ can be associated with vibrations of $\mathrm{C}-\mathrm{O}-\mathrm{C}, \mathrm{C}-\mathrm{O}, \mathrm{C}=\mathrm{C}$ and $\mathrm{C}-\mathrm{C}-\mathrm{O}$ groups. Their intensity is strictly related to the incorporation of cellulosic fillers and correlates with the high intensity of corresponding signals on spectra of used fillers. Absorption bands ( $\mathrm{o}, \mathrm{p}$ and $\mathrm{q}$ ) observed in the range of $890-740 \mathrm{~cm}^{-1}$ can be attributed to the bending vibrations of $\mathrm{C}-\mathrm{H}$ bonds and skeletal vibrations of $\mathrm{C}-\mathrm{C}$ bonds in aliphatic chains of elastomer.

Thermogravimetric analysis

The results of the thermogravimetric analysis of natural rubber based biocomposites are presented in Fig. 9 and summarized in Table 5. Presented data indicate significant decrease of the thermal stability with the addition of cellulosic fillers, which is related to the rather poor thermal stability of used fillers in comparison to pure NR matrix. 

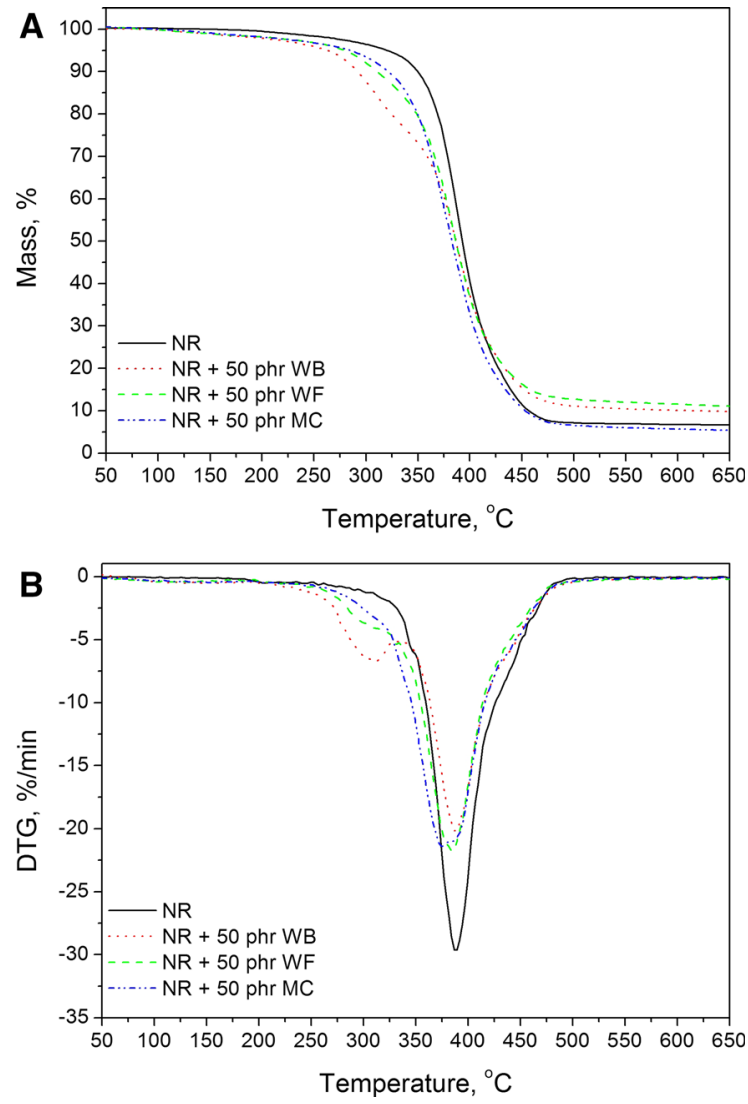

Fig. 9 TGA and DTG curves determined for biocomposites

Moreover, noticeable differences have been observed between samples filled with WB and other fillers. Such phenomenon is associated with different chemical composition of applied cellulosic fillers. Wheat bran, except cellulose, contains significant amounts of hemicellulose, lignin and other compounds (e.g. proteins, starch) and according to literature reports, decomposition of hemicellulose and lignin occurs in lower temperature range in comparison to cellulose (Chapple and Anandjiwala 2010). Hemicellulose and lignin present in cell walls of wheat bran begin to decompose even before reaching $150{ }^{\circ} \mathrm{C}$, while decomposition of the cellulose, resulting in formation of volatiles and char, starts around $200{ }^{\circ} \mathrm{C}$ (Fan and Naughton 2016).

As it can be seen in differential thermogravimetric (DTG) curves, for sample NR $+50 \mathrm{phr} \mathrm{WB}$, there is a noticeable peak at $310.4{ }^{\circ} \mathrm{C}$, related to the degradation of components present in wheat bran. Similar peak was observed in case of thermal degradation of pure wheat bran $\left(309.4{ }^{\circ} \mathrm{C}\right)$. For the samples $\mathrm{NR}+50 \mathrm{phr}$ $\mathrm{WF}$ and $\mathrm{NR}+50 \mathrm{phr}$ MC only one peak is observed on DTG curves, due to the overlapping of peaks characteristic for natural rubber and cellulose present in wood flour and microcellulose. However, it can be seen that addition of cellulosic fillers shifts position of peak towards lower temperatures. Such signal is very characteristic for cellulose materials, which show rapid mass loss around $360{ }^{\circ} \mathrm{C}$ (Gao and Dai 2006).

Dynamic mechanical analysis

In the Fig. 10 the influence of the type of cellulosic filler on the storage modulus $\left(\mathrm{E}^{\prime}\right)$ as a function of temperature is shown. The lowest values of $\mathrm{E}^{\prime}$ in the glassy region were observed for unfilled NR, while the highest values $E^{\prime}$ in the glassy region were measured for sample $\mathrm{NR}+50 \mathrm{phr} \mathrm{MC}$. The values of $\mathrm{E}^{\prime}$ modulus correspond with the values of hardness and cross-link density of obtained biocomposites.

The plots of loss tangent $(\tan \delta)$ as function of temperature are presented in Fig. 11. As it can be seen, addition of fillers not only shifts the temperature position of maximum value of $\tan \delta$ peak, but also lowers the peak magnitude, which can be correlated
Table 5 Thermal decomposition characteristics of prepared biocomposites

\begin{tabular}{|c|c|c|c|c|c|c|}
\hline \multirow[t]{3}{*}{ Sample } & \multicolumn{4}{|c|}{ Mass loss (\%) } & \multirow[t]{3}{*}{$\mathrm{T}_{\max 1}\left({ }^{\circ} \mathrm{C}\right)$} & \multirow[t]{3}{*}{$\mathrm{T}_{\max 2}\left({ }^{\circ} \mathrm{C}\right)$} \\
\hline & 2 & 5 & 10 & 50 & & \\
\hline & \multicolumn{4}{|c|}{ Temperature $\left({ }^{\circ} \mathrm{C}\right)$} & & \\
\hline WB & 111.7 & 225.3 & 265.3 & 336.8 & 309.4 & - \\
\hline WF & 188.8 & 263.3 & 288.8 & 364.7 & - & 373.3 \\
\hline $\mathrm{MC}$ & 175.6 & 288.5 & 311.1 & 360.4 & - & 367.4 \\
\hline NR & 264.8 & 320.7 & 349.8 & 392.7 & - & 388.0 \\
\hline $\mathrm{NR}+50 \mathrm{phr} \mathrm{WB}$ & 193.4 & 262.8 & 292.0 & 386.6 & 310.4 & 388.1 \\
\hline $\mathrm{NR}+50 \mathrm{phr} \mathrm{WF}$ & 209.6 & 280.0 & 310.8 & 386.4 & - & 385.0 \\
\hline $\mathrm{NR}+50 \mathrm{phr} \mathrm{MC}$ & 208.4 & 285.2 & 321.6 & 382.7 & - & 374.7 \\
\hline
\end{tabular}




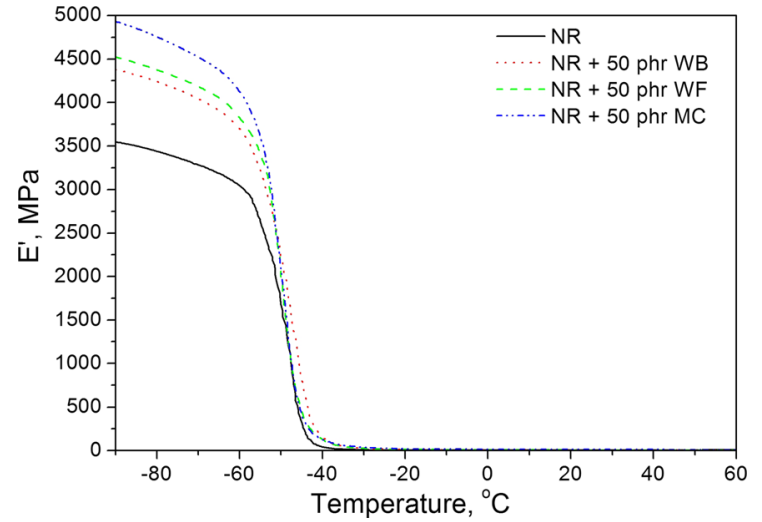

Fig. 10 Storage modulus of biocomposites as a function of temperature

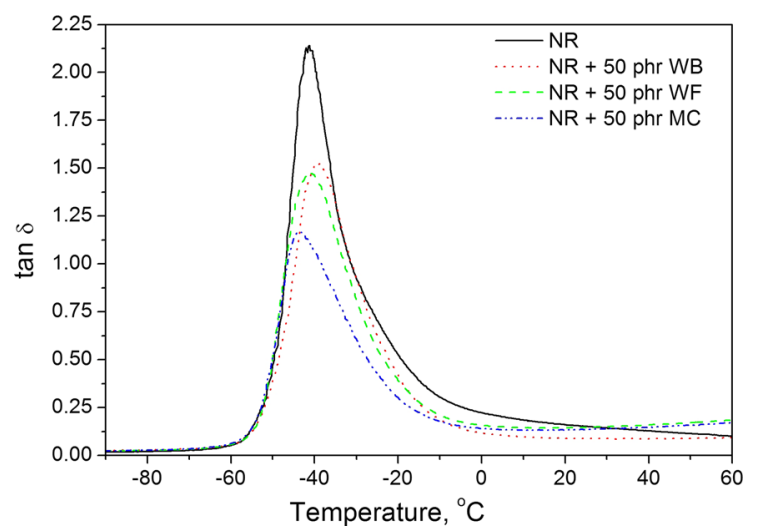

Fig. 11 Plot of $\tan \delta$ of biocomposites as a function of temperature

with the reduced mobility of polymer chains at the matrix-filler interface. This indicates better adhesion at the matrix-filler interface and is in agreement with previous studies (Cao et al. 2005; Sormana and Meredith 2004; Tarakcilar 2011). Bindu and Thomas, based upon the information and formulas presented by Abdalla and Kojima (Abdalla et al. 2007; Bindu and Thomas 2013; Kojima et al. 1993), proposed a method for calculation of the amount of polymer chains immobilized through matrix-filler interactions in accordance with formula (12):

$\mathrm{C}_{v}=1-\frac{\left(1-C_{\mathrm{o}}\right) \mathrm{W}}{\mathrm{W}_{\mathrm{o}}}$

where $\mathrm{C}_{\mathrm{v}}$ is the volume fraction of the immobilized polymer chains, $\mathrm{C}_{\mathrm{o}}$ stands for the volume fraction of the immobilized chains in the pure natural rubber (taken to be 0 ), and $\mathrm{W}$ and $\mathrm{W}_{\mathrm{o}}$ are energy loss fractions for analyzed sample and pure NR, respectively. Energy loss fraction $\mathrm{W}$ can be calculated from the $\tan \delta$ in accordance to the following relation (13):

$\mathrm{W}=\frac{\pi \cdot \tan \delta}{\pi \cdot \tan \delta+1}$

Glass transition temperatures $\left(\mathrm{T}_{\mathrm{g}}\right)$ and volume fractions $\left(\mathrm{C}_{\mathrm{v}}\right)$ of immobilized polymer chains are presented in Table 6. Glass transition temperature of prepared biocomposites $\left(\mathrm{T}_{\mathrm{g}}\right)$ was determined as the position of the maximum on the loss tangent curve $(\tan \delta$ ) versus temperature. For comparison, $\mathrm{T}_{\mathrm{g}}$ as position of maxima on the loss modulus curve $\left(\mathrm{E}^{\prime \prime}\right)$ versus temperature was also presented. It can be clearly seen that $T_{g}$ and $C_{v}$ values depend strongly on the characteristics of applied filler. The lowest $C_{v}$ value were determined for the composite containing wheat bran, which can be associated with chemical structure of this filler. Proteins (around $4 \mathrm{wt} \%$ ) present in WB may act like a plasticizers simultaneously enhancing the molecular motion in prepared composite (Hejna et al. 2015). This phenomenon decreases porosity of obtained biocomposites (see Table 3), which affects glass transition temperature (Kasapis et al. 2007). This explains the highest value of glass transition temperature in case of sample $\mathrm{NR}+50 \mathrm{phr} \mathrm{WB}$ comparing to samples filled with WF or MC.

For better understanding the interfacial interactions between NR and used cellulosic fillers, the adhesion factor (A) was calculated from dynamic mechanical analysis results (Wei et al. 2015). Kubát et al (1990) assumed that the loss factor of the composite $\left(\tan \delta_{c}\right)$ can be expressed in terms of volume fraction and mechanical damping of filler, interface and polymer matrix by presented formula (14):

$\tan \delta_{c}=V_{f} \tan \delta_{f}+V_{i} \tan \delta_{i}+V_{m} \tan \delta_{m}$

where $c, f, i$ and $m$ subscripts denote biocomposite, filler, interphase and matrix, while $\mathrm{V}$ is the filler volume fraction of each phase.

Assuming that the damping of the filler can be considered very low, because of its rigidity and the volume fraction of the interface is even lower and can be neglected comparing to its filler and matrix counterparts, formula (15) may be rearranged into:

$\frac{\tan \delta_{c}}{\tan \delta_{m}} \cong\left(1-V_{f}\right)(1+\mathrm{A})$

where adhesion factor is described by following formula (16): 
Table 6 Glass transition temperatures, volume fractions of immobilized polymer chains and adhesion factors of the biocomposites

\begin{tabular}{llllr}
\hline Properties & \multicolumn{2}{l}{ Sample } & & \\
\cline { 2 - 5 } & $\mathrm{NR}$ & $\mathrm{NR}+50 \mathrm{phr}$ WB & $\mathrm{NR}+50 \mathrm{phr}$ WF & $\mathrm{NR}+50 \mathrm{phr} \mathrm{MC}$ \\
\hline $\mathrm{T}_{\mathrm{g}}$ (with respect to tan $\left.\delta \max \right)\left({ }^{\circ} \mathrm{C}\right)$ & -41.19 & -39.22 & -41.50 & -43.15 \\
$\mathrm{~T}_{\mathrm{g}}$ (with respect to $\left.\mathrm{E}^{\prime \prime} \max \right)\left({ }^{\circ} \mathrm{C}\right)$ & -48.48 & -47.61 & -49.48 & -49.30 \\
$\mathrm{E}^{\prime}$ at $25{ }^{\circ} \mathrm{C}(\mathrm{MPa})$ & 5.00 & 6.67 & 6.51 & 11.01 \\
$\tan \delta$ at $25\left({ }^{\circ} \mathrm{C}\right)$ & 0.15 & 0.09 & 0.15 & 0.13 \\
$\mathrm{C}_{\mathrm{v}}$ & 0 & 0.0498 & 0.0552 & 0.0977 \\
$\mathrm{~A}$ & - & 0.0211 & -0.0808 & -0.3467 \\
\hline
\end{tabular}

$\mathrm{A}=\left(\frac{V_{i}}{1-V_{f}}\right)\left(\frac{\tan \delta_{i}}{\tan \delta_{m}}\right)$

Formula (15) could be rewritten and adhesion factor may be expressed in terms of the relative damping of biocomposite and pure polymer and the volume fraction of filler assuming that the transcrystallinity layer at the interphase may be neglected, because of the rather low fiber aspect ratio of applied fillers. Such rearrangement of the formula (17) leads to:

$\mathrm{A}=\left(\frac{1}{1-V_{f}}\right)\left(\frac{\tan \delta_{c}}{\tan \delta_{m}}\right)-1$

A low value for A indicates high level of interface adhesion and enhanced interactions between the matrix and filler particles (Wei et al. 2013). The A values for analyzed samples are presented in Table 6. Adhesion factor values are in line with the presented values of $\mathrm{C}_{\mathrm{v}}$, which suggest the highest matrix-filler adhesion for samples containing MC and the lowest for NR/WB biocomposite. Presented calculations explain the differences in static mechanical properties between studied biocomposites. Negative values of adhesion factor in case of samples containing wood flour and microcellulose can be associated with the simplification of model and neglecting of the filler anisotropy and with development of the interphase region, which obviously have slight influence on the macromolecular mobility at the filler surroundings (Correa et al. 2007).

\section{Scanning electron microscopy}

The influence of the type of cellulosic filler on morphology of biocomposites is presented in the Fig. 12. Presented images demonstrate surface of biocomposites after extraction with toluene $(72 \mathrm{~h}$, at room temperature). The applied methodology allows effective assessment of voids formed during extraction, which are related to two factors. First of them is the amount of soluble fraction (e.g. unbonded elastomer) present in biocomposites. The second factor affecting, is possible separation of cellulosic filler from NR matrix due to permanent stress acting on NR matrix during swelling. This is associated with solvent absorption capacity of biocomposites, which is limited by matrix-filler interactions and cross-link density of the biocomposites. It was observed that MC was well-embedded in the natural rubber matrix, comparing to WB and WF. Significant differences in its dispersion is due to different particle size distribution of MC and WB or WF filler (see Fig. 1). Particle size of WB and WF filler was similar, however the morphology of biocomposties obtained with these fillers was clearly different (Figs. 12b, c). This confirms significant influence of chemical composition and crystalline structure of cellulose on matrix-filler interactions. As mentioned before, unlike commercial cellulosic fillers, wheat bran contains mostly amorphous cellulose (see Fig. 3), which has beneficial impact on matrix-filler interactions. Furthermore, wheat bran contains significant amount of proteins, which can act like plasticizers in NR/WB biocomposites. Better dispersion of WB in NR matrix decreases porosity of NR/WB biocomposites. Additionally, recently Jong (2015) proved that wheat gluten can act like reinforcement of natural rubber. Above mentioned factors, explain more developed surface in case of sample $\mathrm{NR}+50 \mathrm{phr}$ $\mathrm{WB}$, comparing to sample $\mathrm{NR}+50 \mathrm{phr} \mathrm{WF}$. The presented SEM images confirm the results of curing characteristics, mechanical and thermal properties of the obtained biocomposites. 

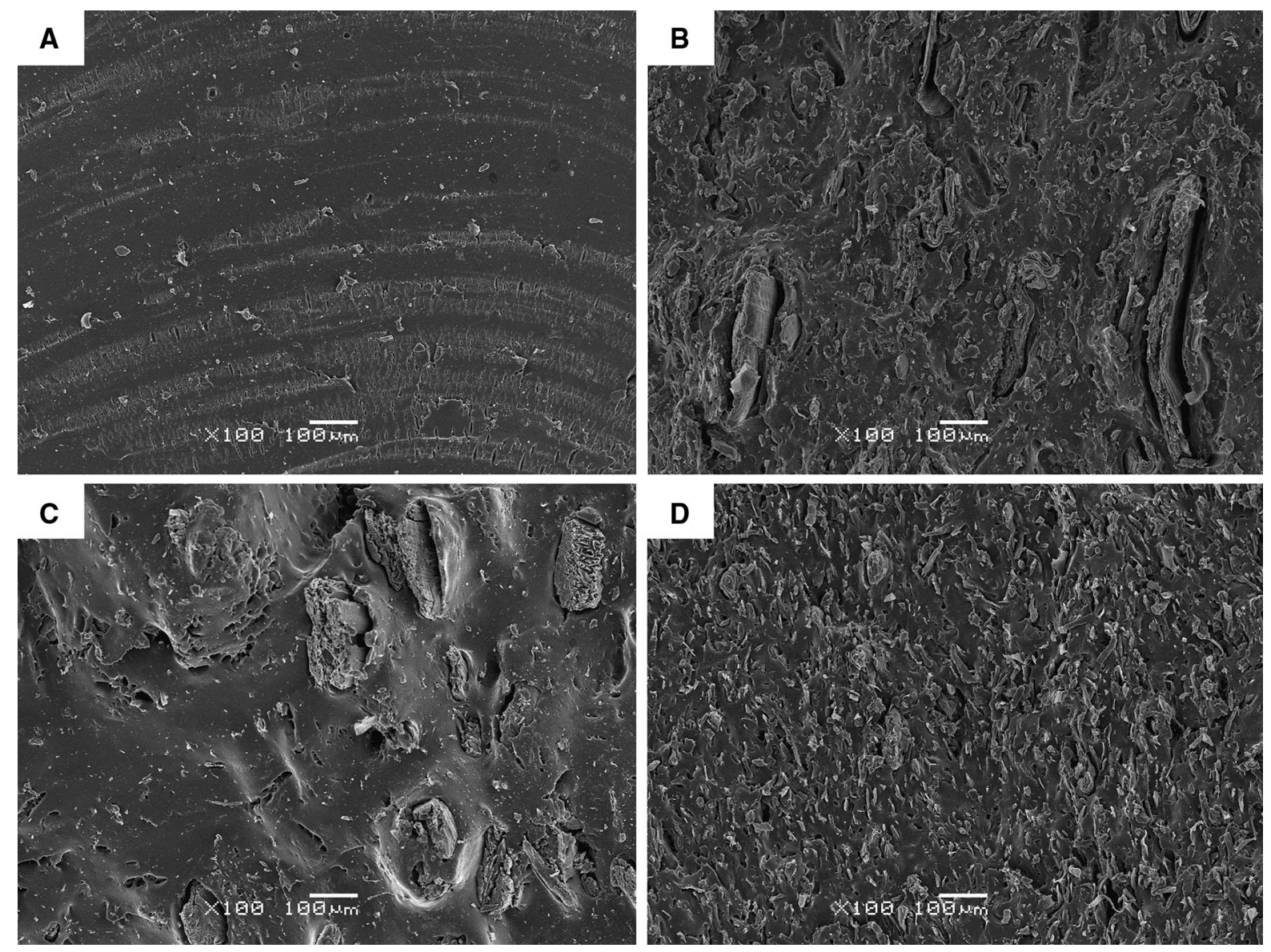

Fig. 12 SEM images of biocomposites surface after swelling tests (magnification $\times 100$ ): a unfilled NR, b NR +50 phr WB, c NR $+50 \mathrm{phr}$ WF and d NR $+50 \mathrm{phr} \mathrm{MC}$

\section{Conclusions}

Natural rubber based biocomposites filled with varying content of wheat bran were prepared using internal mixer and followed by cross-linking with sulfur curing system. For better understanding of the interfacial interactions between natural rubber and wheat bran, the properties of the prepared biocomposites were compared with those filled with two commercial cellulosic fillers: wood flour and microcellulose. The obtained biocomposites were examined for structure, processing, physico-mechanical, swelling, thermal and morphological properties. Reinforcing activity of applied cellulosic fillers was evaluated using a Wolff activity coefficient. The obtained results suggest reinforcing effect of applied fillers, which increases with content of filler. It was noticed that reinforcing activity of cellulosic fillers did not correspond with the results of mechanical properties, which can be related to strain inducted crystallization of natural rubber. Higher amount of cellulosic filler in natural rubber matrix limited mobility of polymer chains, which was confirmed by the results of modulus at 100/300 \% elongation, hardness, crosslink density and dynamic mechanical analysis. This phenomenon resulted in very limited strain-induced crystallization of natural rubber matrix. The results have shown that comparing to commercial cellulosic fillers, presence of amorphous cellulose and high content of amino-acids in the wheat bran has a beneficial influence on processing, physico-mechanical and morphological properties of the biocomposites. Furthermore, high content of macro- and microelements present in wheat bran may affect in positive way on further biodegradation of the biocomposites. 
This work confirms that wheat bran can be successfully applied as low-cost alternative for "conventional" cellulosic fillers in elastomeric composites. Furthermore, presented results indicate that further studies on that field should focus on: (1) evaluation the impact of proteins, macro- and microelements present in cellulosic filler on biodegradation efficiency of biocomposites; (2) optimization of NR based biocomposites' processing and curing conditions (e.g. applied curing system); (3) application of WB together with other fillers (e.g. nanofillers) as "hybrid fillers" in biocomposites.

Acknowledgments We thank Prof. Maria Gazda at Faculty of Applied Physics and Mathematics, Gdansk University of Technology for XRD measurements and valuable help during description of obtained results. This research received no specific grant from any funding agency in the public, commercial or not-for-profit sectors.

Open Access This article is distributed under the terms of the Creative Commons Attribution 4.0 International License (http:// creativecommons.org/licenses/by/4.0/), which permits unrestricted use, distribution, and reproduction in any medium, provided you give appropriate credit to the original author(s) and the source, provide a link to the Creative Commons license, and indicate if changes were made.

\section{References}

Abdalla M, Dean D, Adibempe D, Nyairo E, Robinson P, Thompson G (2007) The effect of interfacial chemistry on molecular mobility and morphology of multiwalled carbon nanotubes epoxy nanocomposite. Polymer 48:5662-5670

Agarwal UP, Reiner RS, Ralph SA (2010) Cellulose I crystallinity determination using FT-Raman spectroscopy: univariate and multivariate methods. Cellulose 17:721-733

Avolio R, Graziano V, Pereira YDF, Cocca M, Gentile G, Errico ME, Ambrogi V, Avella M (2015) Effect of cellulose structure and morphology on the properties of poly(butylene succinate-co-butylene adipate) biocomposites. Carbohydr Polym 133:408-420

Bernardinelli OD, Lima MA, Rezende CA, Polikarpov I, deAzevedo ER (2015) Quantitative ${ }^{13} \mathrm{C}$ MultiCP solid-state NMR as a tool for evaluation of cellulose crystallinity index measured directly inside sugarcane biomass. Biotechnol Biofuels 8:110

Barth A (2007) Infrared spectroscopy of proteins. Biochim Biophys Acta 1767:1073-1101

Berthet MA, Angellier-Coussy H, Machado D, Hilliou L, Staebler A, Vicente A, Gontard N (2015) Exploring the potentialities of using lignocellulosic fibres derived from three food by-products as constituents of biocomposites for food packaging. Ind Crop Prod 69:110-122

Bertran MS, Dale BE (1986) Determination of cellulose accessibility by differential scanning calorimetry. J Appl Polym Sci 32:4241-4253

Bindu P, Thomas S (2013) Viscoelastic behavior and reinforcement mechanism in rubber nanocomposites in the vicinity of spherical nanoparticles. J Phys Chem B 117:12632-12648

Błędzki AK, Franciszczak P, Mamun A (2014) The utilization of biochemically modified microfibers from grain byproducts as reinforcement for polypropylene biocomposite. Express Polym Lett 10:767-778

Błędzki AK, Franciszczak P, Osman Z, Elbadawi M (2015) Polypropylene biocomposites reinforced with softwood, abaca, jute, and kenaf fibers. Ind Crop Prod 70:91-99

Brüning K, Schneider K, Heinrich G (2012) Deformation and orientation in filled rubbers on the nano- and microscale studied by X-ray scattering. J Polym Sci Pol Phys 50:1728-1732

Budarin VL, Clark JH, Lanigan BA, Shuttleworth P, Macquarrie DJ (2010) Microwave assisted decomposition of cellulose: a new thermochemical route for biomass exploitation. Bioresour Technol 101:3776-3779

Cao X, Lee LJ, Widya T, Macosko C (2005) Polyurethane/clay nanocomposites foams: processing, structure and properties. Polymer 46:775-783

Caprez A, Arrigoni E, Amadò R, Neukom H (1986) Influence of different types of thermal treatment on the chemical composition and physical properties of wheat bran. J Cereal Sci 4:233-239

Chapple S, Anandjiwala R (2010) Flammability of natural fiberreinforced composites and strategies for fire retardancy: a review. J Thermoplast Compos Mater 23:871-893

Chikhi M, Agoudjil B, Boudenne A, Gherabli A (2013) Experimental investigation of new biocomposite with low cost for thermal insulation. Energy Build 66:267-273

Ciolacu D, Ciolacu F, Popa VI (2011) Amorphous cellulosestructure and characterization. Cellul Chem Technol 45:13-21

Colom X, Carrillo F, Nogués F, Garriga P (2003) Structural analysis of photodegraded wood by means of FTIR spectroscopy. Polym Degrad Stab 80:543-549

Correa CA, Razzino CA, Hage E (2007) Role of maleated coupling agents on the interface adhesion of polypropylene-wood composites. J Thermoplast Compos Mater 20:323-338

Datta J, Głowińska E (2011) Influence of cellulose on mechanical and thermomechanical properties of elastomers obtained from mixtures containing natural rubber. Polimery 56:823-827

Faix O (1991) Classification of lignins from different botanical origins by ft-ir spectroscopy. Holzforschung 45:21-27

Faludi G, Dora G, Imre B, Renner K, Móczó J, Pukánszky B (2014) PLA/lignocellulosic fiber composites: particle characteristics, interfacial adhesion, and failure mechanism. J Appl Polym Sci 131:39902

Fan M, Naughton A (2016) Mechanisms of thermal decomposition of natural fiber composites. Compos Part B Eng 88:1-10 
Flory PJ, Rehner J (1943) Statistical mechanics of cross-linked polymer networks I. Rubberlike elasticity. J Chem Phys 11:512-520

Franciszczak P, Błędzki AK (2015) Tailoring of dual-interface in high tenacity PP composites-toughening with positive hybrid effect. Compos Part A Appl Sci Manuf. doi:10. 1016/j.compositesa.2015.07.001

French AD (2014) Idealized powder diffraction patterns for cellulose polymorphs. Cellulose 21:885-896

French AD, Cintrón MS (2013) Cellulose polymorphy, crystallite size, and the Segal crystallinity index. Cellulose 20:583-588

Gao M, Dai QJ (2006) Studies on the thermal degradation of cellulosic fibers treated with flame retardants. Chin J Process Eng 6:242-246

Georgiopoulos P, Kontou E (2015) The effect of wood-fiber type on the thermomechanical performance of a biodegradable polymer matrix. J Appl Polym Sci 132:42185

Gurunathan T, Mohanty S, Nayak SK (2015) A review of the recent developments in biocomposites based on natural fibres and their application perspectives. Compos Part A Appl Sci Manuf 77:1-25

Hejna A, Formela K, Saeb MR (2015) Processing, mechanical and thermal behavior assessments of polycaprolactone/ agricultural wastes biocomposites. Ind Crop Prod 76:725-733

Hong H, He H, Jia D, Zhang H (2011) Effect of wood flour on the curing behaviour, mechanical properties, and water absorption of natural rubber/wood flour composites. J Macromol Sci Part B Phys 50:1625-1636

Horvath AL (2006) Structurally complicated materials: I. Wood. J Phys Chem Ref Data 35:77-92

Ismail H, Edyham MR, Wirjosentono B (2002) Bamboo fibre filled natural rubber composites: the effects of filler loading and bonding agent. Polym Test 21:139-144

Jacob M, Thomas S, Varughese KT (2004) Mechanical properties of sisal/oil palm hybrid fiber reinforced natural rubber composites. Compos Sci Technol 64:955-965

Jiang C, He H, Jiang H, Ma L, Jia DM (2013) Nano-lignin filled natural rubber composites: preparation and characterization. Express Polym Lett 7:480-493

Jong L (2015) Toughness of natural rubber composites reinforced with hydrolyzed and modified wheat gluten aggregates. J Polym Environ 23:541-550

Karaağaç B (2014) Use of ground pistachio shell as alternative filler in natural rubber/styrene-butadiene rubber-based rubber compounds. Polym Compos 35:245-252

Karimi K, Taherzadeh MJ (2016) Analytical methods in pretreatment of lignocelluloses: composition, imaging, and crystallinity. Bioresour Technol 200:1008-1018

Kasapis S, Sablani SS, Rahman MS, Al-Marhoobi IM, Al-Amri IS (2007) Porosity and the effect of structural changes on the mechanical glass transition temperature. J Agric Food Chem 55:2459-2466

Khan RA, Beck S, Dussault D, Salmieri S, Bouchard J, Lacroix M (2013) Mechanical and barrier properties of nanocrystalline cellulose reinforced poly(caprolactone) composites: effect of gamma radiation. J Appl Polym Sci 129:3038-3046

Kljun A, Benians TAS, Goubet F, Meulewaeter F, Knox JP, Blackburn RS (2011) Comparative analysis of crystallinity changes in cellulose I polymers using ATR-FTIR, X-ray diffraction, and carbohydrate-binding module probes. Biomacromolecules 12:4121-4126

Kojima Y, Usuki A, Kawasumi M, Okada A, Kurauchi T, Kamigaito O (1993) Sorption of water in nylon 6-clay hybrid. J Appl Polym Sci 49:1259-1264

Korol J, Lenża J, Formela K (2015a) Manufacture and research of TPS/PE biocomposites properties. Compos Part B Eng 68:310-316

Korol J, Burchart-Korol D, Pichlak M (2015b) Expansion of environmental impact assessment for eco-efficiency evaluation of biocomposites for industrial application. J Clean Prod. doi:10.1016/j.jclepro.2015.11.101

Kramárová Z, Alexy P, Chodák I, Špirk E, Hudec I, Koŝíková B, Gregorová A, Š́ri P, Feranc J, Bugaj P, Ďuračka M (2007) Biopolymers as fillers for rubber blends. Polym Adv Technol 18:135-140

Kraus GJ (1963) Swelling of filler-reinforced vulcanizates. J Appl Polym Sci 7:861-871

Kubát J, Rigdahl M, Welander M (1990) Characterization of interfacial interactions in high density polyethylene filled with glass spheres using dynamic-mechanical analysis. J Appl Polym Sci 39:1527-1539

Kwiecień I, Adamus G, Bartkowiak A, Kowalczuk M (2014) Synthesis and structural characterization at the molecular level of oligo(3-hydroxybutyrate) conjugates with antimicrobial agents designed for food packaging materials. Des Monomers Polym 17:311-321

Li X, Tabil LG, Oguocha IN, Panigrahi S (2008) Thermal diffusivity, thermal conductivity, and specific heat of flax fiber-HDPE biocomposites at processing temperatures. Compos Sci Technol 68:1753-1758

Liu R, Peng Y, Cao J, Chen Y (2014) Comparison on properties of lignocellulosic flour/polymer composites by using wood, cellulose, and lignin flours as fillers. Compos Sci Technol 103:1-7

López-Manchado MA, Herrero B, Arroyo M (2003) Preparation and characterization of organoclay nanocomposites based on natural rubber. Polym Int 52:1070-1077

Manaila E, Stelescu MD, Doroftei F (2015) Polymeric composites based on natural rubber and hemp fibers. Iran Polym J 24:135-148

Menon ARR, Pillai CKS, Nando GB (1998) Vulcanization of natural rubber modified with cashew nut shell liquid and its phosphorylated derivative - a comparative study. Polymer 39:4033-4036

Mohammed L, Ansari MNM, Pua G, Jawaid M, Islam MS (2015) A review on natural fiber reinforced polymer composite and its applications. Int J Polym Sci. Article ID 243947

Nam S, French AD, Condon BD, Concha M (2016) Segal crystallinity index revisited by the simulation of X-ray diffraction patterns of cotton cellulose I $\beta$ and cellulose II. Carbohydr Polym 135:1-9

Peltola H, Pääkkönen E, Jetsu P, Heinemann S (2014) Wood based PLA and PP composites: effect of fibre type and matrix polymer on fibre morphology, dispersion and composite properties. Compos Part A Appl Sci Manuf 61:13-22

Proniewicz LM, Paluszkiewicz C, Wesełucha-Birczyńska A, Majcherzyk H, Barański A, Konieczna A (2001) FT-IR and 
FT-Raman study of hydrothermally degradated cellulose. J Mol Struct 596:163-169

Raza MA, Ashraf MA, Westwood AVK, Jamil T, Ahmad R, Inamm A, Deen KM (2014) Maleated high oleic sunflower oil-treated cellulose fiber-based styrene butadiene rubber composites. Polym Compos. doi:10.1002/pc.23273

Ren Y, Zhao R, Yao Q, Li Q, Zhang X, Zhang L (2015) Effects of plasticizers on the strain-induced crystallization and mechanical properties of natural rubber and synthetic polyisoprene. RSC Adv 5:11317-11324

Sałasińska K, Ryszkowska J (2015) The effect of filler chemical constitution and morphological properties on the mechanical properties of natural fiber composites. Compos Interfaces 22:39-50

Sareena C, Ramesan MT, Purushothaman E (2012a) Utilization of coconut shell powder as a novel filler in natural rubber. J Reinf Plast Compos 31:533-547

Sareena C, Ramesan MT, Purushothaman E (2012b) Utilization of peanut shell powder as a novel filler in natural rubber. J Appl Polym Sci 125:232-234

Saunders RM (1978) Wheat bran: composition and digestibility. In: Spiller GA (ed) Topics in dietary fiber research, 1st edn. Plenum Press, New York, pp 43-58

Schwanninger M, Rodrigues JC, Pereira H, Hinterstoisser B (2004) Effects of short-time vibratory ball milling on the shape of FT-IR spectra of wood and cellulose. Vib Spectrosc 36:23-40

Selmin F, Franceschini I, Cupone IE, Minghetti P, Cilurzo F (2015) Aminoacids as non-traditional plasticizers of maltodextrins fast-dissolving film. Carbohydr Polym 115:613-616

Shen CH, Springer GS (1976) Moisture absorption and desorption of composite materials. J Compos Mater 10:2-20

Shen L, Haufe J, Patel MK (2009) Product overview and market projection of emerging biobased plastics. Report No: NWS-E-2009-32 The Netherlands: Utrecht

Sobczak L, Brüggemann O, Putz RF (2013) Polyolefin composites with natural fibers and wood-modification of the fiber/filler-matrix interaction. J Appl Polym Sci 127:1-17

Sormana JL, Meredith JC (2004) High-throughput discovery of structure-mechanical property relationships for segmented Poly(urethane-urea)s. Macromolecules 37:2186-2195

Stein TM, Gordon SH, Greene RV (1999) Amino acids as plasticizers: II. Use of quantitative structure-property relationships to predict the behavior of monoammoniummonocarboxylate plasticizers in starch-glycerol blends. Carbohydr Polym 39:7-16

Stein TM, Greene RV (1997) Amino acids as plasticizers for starch-based plastics. Starch 49:245-249

Tarakcilar AR (2011) The effects of intumescent flame retardant including ammonium polyphosphate/pentaerythritol and fly ash fillers on the physicomechanical properties of rigid polyurethane foams. J Appl Polym Sci 120:2095-2102

Teuber L, Osburg VS, Toporowski W, Militz H, Krause A (2016) Wood polymer composites and their contribution to cascading utilization. J Clean Prod 110:9-15

Tomaszewska-Ciosk E, Golachowski A, Zdybel E (2013) Determination of biodegradation rate of carrier for microorganism immobilization fabricated based on starch. Pol J Chem Technol 15:110-114

Tsuboi T, Yoshino T, Mori M (2012) Improvement of physical properties of poly(lactic acid) by adding amorphous cellulose. Seikei-Kakou 24:612-617

Wei L, Liang S, McDonald AG (2015) Thermophysical properties and biodegradation behavior of green composites made from polyhydroxybutyrate and potato peel waste fermentation residue. Ind Crop Prod 69:91-103

Wei L, McDonald AG, Freitag C, Morrell JJ (2013) Effects of wood fiber esterification on properties, weatherability and biodurability of wood plastic composites. Polym Degrad Stab 98:1348-1361

Xu F, Yu J, Tesso T, Dowell F, Wang D (2013) Qualitative and quantitative analysis of lignocellulosic biomass using infrared techniques: a mini-review. Appl Energy 104:801-809

Yona AMC, Budija F, Kricej B, Kutnara A, Pavlic M, Pori P, Tavzes C, Petric M (2014) Production of biomaterials from cork: liquefaction in polyhydric alcohols at moderate temperatures. Ind Crop Prod 54:296-301

Yue Y, Han J, Han G, Zhang Q, French AD, Wu Q (2015) Characterization of cellulose I/II hybrid fibers isolated from energycane bagasse during the delignification process: morphology, crystallinity and percentage estimation. Carbohydr Polym 133:438-447

Zhou Y, Fan M, Che L, Zhuang J (2015) Lignocellulosic fibre mediated rubber composites: an overview. Compos Part B Eng 76:180-191 